\title{
Mucosal Architectural Rearrangement in Coeliac Disease
}

\author{
Erna Sziksz ${ }^{1,2, *}$, Apor Veres-Székely ${ }^{1,2}$, Domonkos Pap ${ }^{2}$, Andrea Fekete ${ }^{2,3}$, Gábor Veres ${ }^{1}$, Tivadar Tulassay ${ }^{1,2}$, \\ Attila Szabó ${ }^{2}$, Ádám Vannay ${ }^{1,2}$ \\ ${ }^{1}$ MTA-SE, Pediatrics and Nephrology Research Group, H-1083, Budapest, Hungary \\ ${ }^{2}$ First Department of Pediatrics, Semmelweis University, H-1083, Budapest, Hungary \\ ${ }^{3}$ MTA-SE, Lendület Diabetes Research Group, H-1083 Budapest, Hungary \\ *Corresponding author: sziksz.erna@med.semmelweis-univ.hu
}

Received July 09, 2014; Revised September 10, 2014; Accepted September 17, 2014

\begin{abstract}
Celiac disease (CD) is the most common autoimmune enteropathy in the western world caused by the intolerance to gluten in genetically predisposed individuals. $\mathrm{CD}$ is characterized by a remarkable rearrangement of the mucosal architecture, in which process myofibroblasts play a crucial role. Myofibroblasts (intestinal subepithelial myofibroblasts and interstitial cells of Cajal) are the most represented mesenchymal cell types in the gut mucosa and are involved in a broad range of biological processes including growth, mucosal protection, repair, inflammation and fibrosis. Myofibroblasts actively contribute to the mucosal changes in $\mathrm{CD}$ due to their ability to produce an excessive amount of extracellular matrix and basement membrane components (e.g. collagens, fibronectin, and specific enzymes including tissue transglutaminases) and through the expression of matrix metalloproteinases (MMPs) and tissue inhibitors of matrix metalloproteinases (TIMPs). The enhanced production of ECM components and MMPs and the altered shape and motility of myofibroblasts in the duodenal mucosa of patients with CD suggest that myofibroblasts may play an essential role in the pathogenesis of CD.
\end{abstract}

Keywords: celiac disease, myofibroblast, extracellular matrix, tissue transglutaminase, matrix metalloproteinase

Cite This Article: Erna Sziksz, Apor Veres-Székely, Domonkos Pap, Andrea Fekete, Gábor Veres, Tivadar Tulassay, Attila Szabó, and Ádám Vannay, "Mucosal Architectural Rearrangement in Coeliac Disease." International Journal of Celiac Disease, vol. 2, no. 3 (2014): 89-92. doi: 10.12691/ijcd-2-3-5.

\section{Introduction}

Celiac disease (CD) is an autoimmune enteropathy characterized by villous atrophy, crypt hyperplasia and rearrangement of the mucosal architecture resulting in two to three-fold increased depth of the lamina propria [34]. In genetically susceptible individuals inflammation is triggered by dietary gluten and related prolamins present in wheat, rye and barley $[4,12,31]$. The chronic inflammation leads to injury of the epithelial barrier thus facilitating the entry of dietary antigens into the lamina propria [32]. Intestinal myofibroblasts were shown to influence the recruitment and activation of immune cells and repair mechanisms through their ability to produce chemokines, cytokines and extracellular matrix components [1]. In the present review we give an overview about the mucosal architectural rearrangement in $\mathrm{CD}$ with special focus on the role of intestinal myofibroblasts.

\section{Intestinal Myofibroblasts}

Intestinal fibroblasts and myofibroblasts are the most represented mesenchymal cell types in the gut mucosa [24]. Definitely myofibroblasts are spindle or stellate- shaped cells that are positive for $\alpha$-smooth muscle actin $(\alpha$-SMA), vimentin, desmin and fibronectin and lack of the epithelial markers, such as cytokeratins and are considered as activated fibroblasts [7,11].

In the intestinal lamina propria there are two distict populations of myofibroblasts, the interstitial cells of Cajal and the intestinal subepithelial myofibroblasts (SEMFs) [23]. Interstitial cells of Cajal are located in an intramuscular space between the submucosa and muscularis propria [27] (Figure 1). They serve as pacemakers, which generate slow electrical waves and stimulates smooth muscle cells leading to their contraction [26]. Furthermore interstitial cells of Cajal were shown to be involved in the regulation of neurotransmission as well [15].

The other group of myofibroblasts in the gut, the SEMFs are mainly localized directly under the epithelial cell layer of the villi and crypts and form a fenestrated innervated sheath next to the vasculature (Figure 1).

During ontogenesis myofibroblasts appear at the 18.5th embryonic day in mice and at the 21st week in humans $[18,28]$. Regarding their origin they can differentiate from mesenchymal cells including fibroblasts, stellate cells, pericytes and smooth muscle cells. Other hypothesis suggest that myofibroblasts can originate from epithelial and endothelial cells through the processes of epithelialmesenchymal and endothelial-mesenchymal transition 
[14,22]. Moreover, myofibroblasts can derivate from bone $\quad$ marrow stem cells as well [3] (Figure 2).

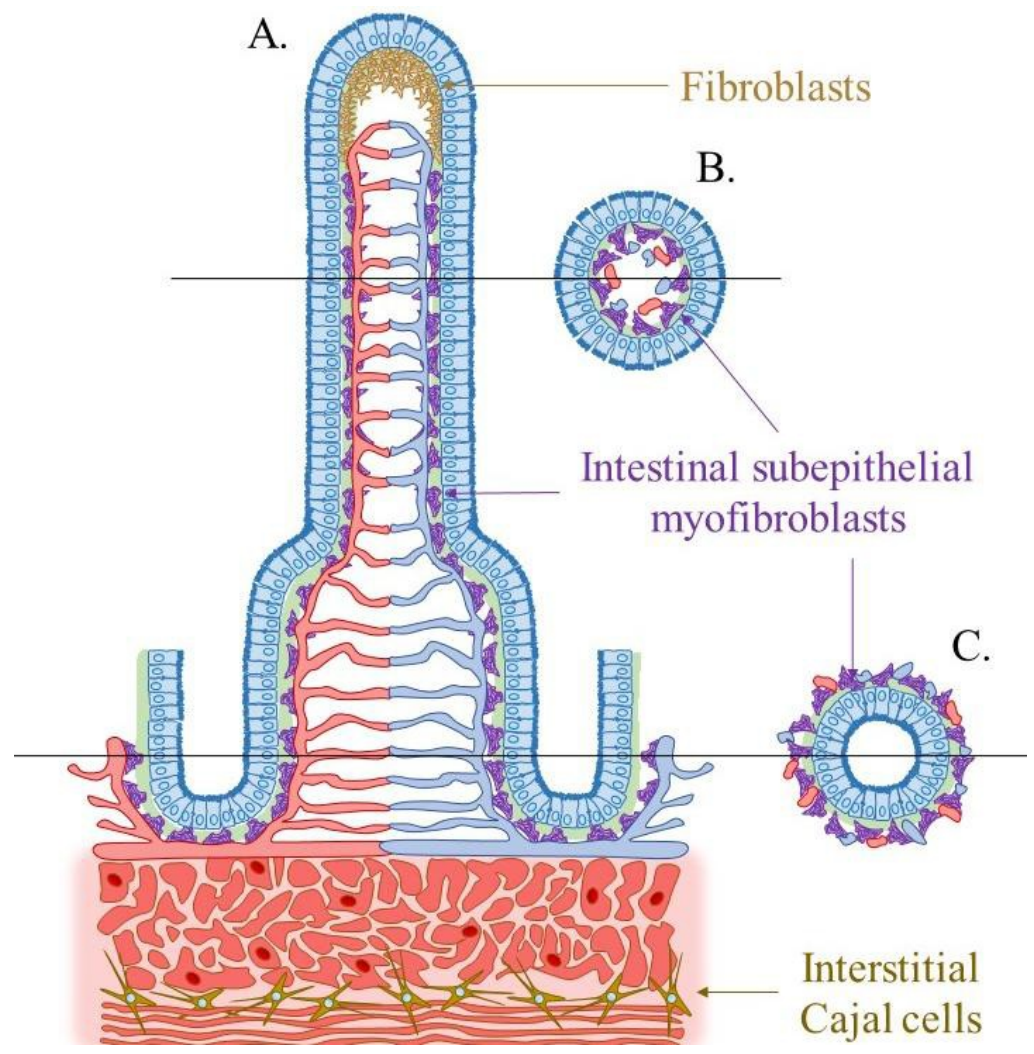

Figure 1. Localization of fibroblasts, intestinal subepithelial myofibroblasts and interstitial Cajal cells in the duodenum. Fibroblasts are localized in the apical region of the villi. Intestinal epithelial myofibroblasts are shown in the longitudinal (A) and cross section of the villus (B) and the crypt (C). Interstitial Cajal cells are found in the intramuscular space. Based on the work of Powell et al [24]

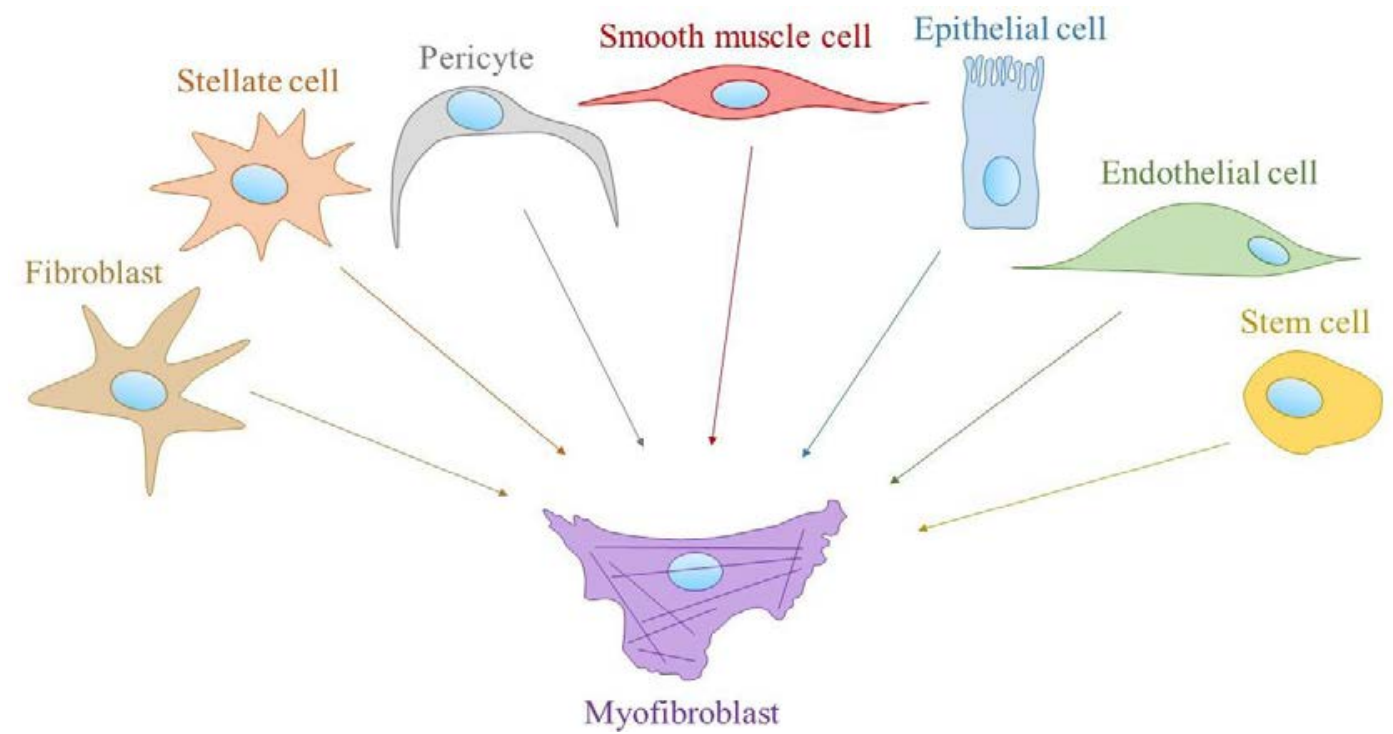

Figure 2. Origin of myofibroblasts. Myofibroblasts can differentiate from several cell types including other mesenchymal cells, epithelial, endothelial and stem cells

Intestinal SEMFs are involved in a broad range of biological processes including growth, mucosal protection, repair, inflammation and fibrosis [30]. The major function of SEMFs is the secretion of the components of the basement membrane and the extracellular matrix (ECM). The intestinal cells are connected to the ECM components via their adhesion receptors (e.g. integrins) localized in their cell surface membrane [1]. Alterations in the chemical composition or mechanical status of the ECM trigger signal transduction through these transmembrane receptors, which result in changes of the cell cycle, shape and/or motility. Indeed ECM coordinates the cellular functions and provides support and nutrition to the epithelium. In this way myofibroblasts contribute to the maintenance of tissue homeostasis [17].

The ECM is composed mainly by fibrillar collagens, containing primarily type I and III collagens or type IV collagen, which latter is one of the major components of a basement membrane forming the intestinal barrier. Besides collagens ECM consists of glycoproteins (fibronectin) and proteoglycans building up a complex molecular network [30] (Figure 3). 


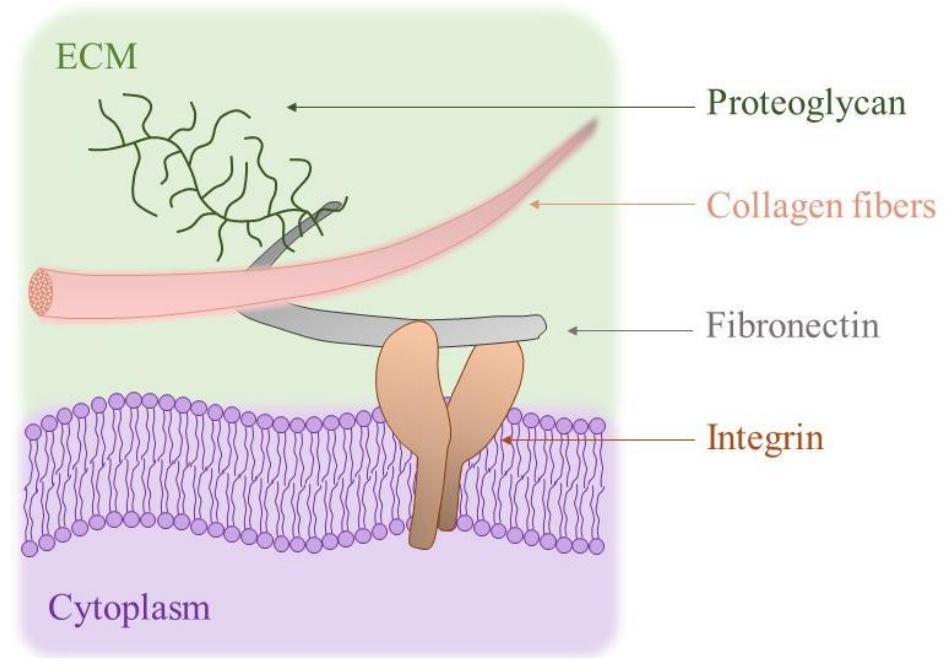

Figure 3. Major components of the extracellular matrix (ECM). Transmembrane receptors such as integrins, which are localized in the cell surface membrane, connect the cells to the ECM components

\section{Mucosal Rearrangement in CD}

Under normal circumstances the intestinal mucosal architecture is maintained and continuously controlled by the interactions among epithelial, mesenchymal and immune cells [16]. This sensitive balance is disturbed in patients with CD [2]. CD is characterized by a remarkable rearrangement of the mucosal architecture, in which process myofibroblasts were shown to play a crucial role.

Characteristic architectural changes in patients with CD include the flat duodenal mucosa surface with seriously damaged epithelium and elevated number of intraepithelial immune cells, thickened basement membrane and elongated crypts [33]. The lamina propria is increased two to threefold with excessive deposition of ECM compared to that of healthy individuals [9]. Myofibroblasts, the major sources of the ECM in CD, secrete large amounts of ECM molecules, which process is modulated by several proinflammatory cytokines and growth factors. Interleukin (IL)- $1 \beta$ and tumor necrosis factor (TNF)- $\alpha$ were demonstrated to induce the production of collagen I and IV in intestinal SEMFs [21]. Another known profibrotic protein, tumor growth factor (TGF)- $\beta$, is able to activate myofibroblasts inducing the synthesis of type I collagen and stimulating the expression of $\alpha$-smooth muscle actin and the formation of stress fibers [29]. For the development of the typical threedimensional structure of ECM, specific enzymes are needed which are also secreted by myofibroblasts. The most important of such enzymes is type 2 transglutaminase (TG2), which has the ability to catalyze the formation of isopeptide bonds resulting in covalent cross-linking of the protein chain via a glutamine residue to the lysine residue of another protein chain [10]. TG2 is anchored at the external surface of cell membranes or it is associated with fibronectin thus modulating cell adhesion and stabilizing the integrin-ECM interaction [36]. In patients with CD immunoglobulin (Ig)A autoantibodies against TG2 as an endomysial autoantigen are present leading to biological dysfunctions [8]. These antibodies disturb the TGF- $\beta$ mediated crosstalk between myofibroblasts and enterocytes resulting in the inhibition of enterocyte differentiation and increased epithelial cell proliferation. This finding indicates that certain components of the ECM may function as autoantigens and the CD-specific autoantibodies contribute to the formation of gluten-triggered architectural alterations of the mucosa in CD [13].

The degradation of ECM components are controlled by a fine balance between matrix metalloproteinases (MMPs) and tissue inhibitors of metalloproteinases (TIMPs) produced by fibroblasts, myofibroblasts, epithelial cells and immune cells including macrophages, neutrophils, eosinophils and lymphocytes [5,19]. MMPs are endopeptidases that play a key role in tissue remodeling through their ability to degrade ECM and basement membrane components in both physiological and pathological conditions [20]. Increased expression of MMP-1, MMP-3, MMP-12 and TIMP-1 was demonstrated in the duodenal mucosa of patients with active CD [6]. Myofibroblasts isolated from active CD patients constitutively expressed MMPs, while those from treated patients (maintained on gluten-free diet) were in a resting condition [5]. Moreover, IL-1 $\beta$ and TNF- $\alpha$ have been shown to induce the expression of MMP-1, MMP-3 and TIMP-1 in SEMFs [35]. These data suggest the key role of MMPs in intestinal tissue injury in CD.

Recently, it was demonstrated that the shape of myofibroblasts isolated from patients with CD differs from that of controls. Furthermore, CD-derived myofibroblasts showed a signet pattern of collagen I and IV, while the control myofibroblasts had a spindle-like geometry. Also the motility and velocity of CD myofibroblasts were decreased compared to that of control individuals [25]. Presumably all these differences in shape and motility of CD-derived myofibroblasts may contribute to the typical architectural changes of the duodenal mucosa observed in CD patients, however further studies are needed to clarify their relevance in the future.

\section{Conclusions}

Architectural rearrangement of the duodenal mucosa is a key feature of CD. Intestinal SEMFs play a critical role in this process through their ability to produce large 
amounts of the components of ECM and basement membrane. Through the production of MMPs and TIMPs intestinal subepithelial myofibroblasts contribute also to the regulation of tissue remodeling.

\section{Acknowledgments}

This work was supported by grants OTKANK84087/2010, -K105530, -K108688, -K 105530, PD83431,“Lendület” Research Grant LP2011-008, and KMR_12-1-2012-0074. Vannay Á and Veres G are holders of the János Bolyai Research grant by János Bolyai Research Scholarship of the Hungarian Academy of Sciences.

\section{Statement of Competing Interests}

The authors have no competing interests.

\section{References}

[1] Andoh A, Bamba S, Fujiyama Y, Brittan M, Wright NA. Colonic subepithelial myofibroblasts in mucosal inflammation and repair: contribution of bone marrow-derived stem cells to the gut regenerative response. J Gastroenterol 2005; 40: 1089-1099.

[2] Briani C, Samaroo D, Alaedini A. Celiac disease: from gluten to autoimmunity. Autoimmun Rev 2008; 7: 644-650.

[3] Brittan M, Hunt T, Jeffery R, Poulsom R, Forbes SJ, HodivalaDilke K, Goldman J, Alison MR, Wright NA. Bone marrow derivation of pericryptal myofibroblasts in the mouse and human small intestine and colon. Gut 2002; 50: 752-757.

[4] Catassi C, Fasano A. Celiac disease. Curr Opin Gastroenterol 2008; 24: 687-691.

[5] Ciccocioppo R, Di Sabatino A, Bauer M, Della Riccia DN, Bizzini F, Biagi F, Cifone MG, Corazza GR, Schuppan D. Matrix metalloproteinase pattern in celiac duodenal mucosa. Lab invest 2005; 85: 397-407.

[6] Daum S, Bauer U, Foss HD, Schuppan D, Stein H, Riecken EO, Ullrich R. Increased expression of mRNA for matrix metalloproteinases-1 and -3 and tissue inhibitor of metalloproteinases- 1 in intestinal biopsy specimens from patients with coeliac disease. Gut 1999; 44: 17-25.

[7] De Wever O, Demetter P, Mareel M, Bracke M. Stromal myofibroblasts are drivers of invasive cancer growth. Int J Cancer. 2008; 123: 2229-2238.

[8] Dieterich W, Ehnis T, Bauer M, Donner P, Volta U, Riecken EO, Schuppan D. Identification of tissue transglutaminase as the autoantigen of celiac disease. Nat Med 1997; 3: 797-801.

[9] Elli L, Bardella MT. Motility disorders in patients with celiac disease. Scand J Gastroenterol 2005; 40: 743-749.

[10] Elli L, Bergamini CM, Bardella MT, Schuppan D. Transglutaminases in inflammation and fibrosis of the gastrointestinal tract and the liver. Dig Liver Dis 2009 41: 541-550.

[11] Eyden B. The myofibroblast: phenotypic characterization as a prerequisite to understanding its functions in translational medicine. J Cell Mol Med 2008; 12: 22-37.

[12] Guandalini S, Assiri A. Celiac Disease: A Review. JAMA pediatr 2014; 168: 272-278.

[13] Halttunen T, Maki M. Serum immunoglobulin A from patients with celiac disease inhibits human T84 intestinal crypt epithelial cell differentiation. Gastroenterology 1999; 116: 566-572.

[14] Hinz B, Phan SH, Thannickal VJ, Galli A, Bochaton-Piallat ML, Gabbiani G. The myofibroblast: one function, multiple origins. Am J Pathol 2007; 170: 1807-1816.

[15] Klein S, Seidler B, Kettenberger A, Sibaev A, Rohn M, Feil R, Allescher HD, Vanderwinden JM, Hofmann F, Schemann M, Rad
R, Storr MA, Schmid RM, Schneider G, Saur D. Interstitial cells of Cajal integrate excitatory and inhibitory neurotransmission with intestinal slow-wave activity. Nat Commun 2013; 4: 1630.

[16] MacDonald TT, Monteleone I, Fantini MC, Monteleone G. Regulation of homeostasis and inflammation in the intestine. Gastroenterology 2011; 140: 1768-1775.

[17] Marastoni S, Ligresti G, Lorenzon E, Colombatti A, Mongiat M. Extracellular matrix: a matter of life and death. Connect Tissue Res 2008; 49: 203-206.

[18] McLin VA, Henning SJ, Jamrich M. The role of the visceral mesoderm in the development of the gastrointestinal tract. Gastroenterology 2009; 136: 2074-2091.

[19] Medina C, Radomski MW. Role of matrix metalloproteinases in intestinal inflammation. J Pharmacol Exp Ther 2006; 318: 933938.

[20] Nelson AR, Fingleton B, Rothenberg ML, Matrisian LM.. Matrix metalloproteinases: biologic activity and clinical implications. $J$ Clin Oncol 2000; 18: 1135-1149.

[21] Okuno T, Andoh A, Bamba S, Araki Y, Fujiyama Y, Fujiyama M, Bamba T. Interleukin-1beta and tumor necrosis factor-alpha induce chemokine and matrix metalloproteinase gene expression in human colonic subepithelial myofibroblasts, Scand $J$ Gastroenterol 2002; 37: 317-324.

[22] Polyak K, Weinberg RA. Transitions between epithelial and mesenchymal states: acquisition of malignant and stem cell traits Nat Rev Cancer 2009; 9: 265-273.

[23] Powell DW, Mifflin RC, Valentich JD, Crowe SE, Saada JI, West AB. Myofibroblasts. II. Intestinal subepithelial myofibroblasts. Am J Physiol 1999; 277: C183-201.

[24] Powell DW, Pinchuk IV, Saada JI, Chen X, Mifflin RC. Mesenchymal cells of the intestinal lamina propria.. Annu Rev Physiol 2011; 73: 213-237.

[25] Roncoroni L, Elli L, Bardella MT, Perrucci G, Ciulla M, Lombardo V, Tomba C, Conte D, Doneda L. Extracellular matrix proteins and displacement of cultured fibroblasts from duodenal biopsies in celiac patients and controls. J Transl Med 2013; 11: 91.

[26] Sanders KM, Koh SD, Ward SM. Interstitial cells of cajal as pacemakers in the gastrointestinal tract. Аnnu Rev Physiol 2006; 68: 307-343.

[27] Sanders KM, Ward SM. Interstitial cells of Cajal: a new perspective on smooth muscle function. $J$ Physiol 2006; 576: 721726.

[28] Sappino AP, Dietrich PY, Skalli O, Widgren S, Gabbiani G. Colonic pericryptal fibroblasts. Differentiation pattern in embryogenesis and phenotypic modulation in epithelial proliferative lesions. Virchows Archiv A Pathol Ana Histopathol 1989; 415: 551-557.

[29] Simmons JG, Pucilowska JB, Keku TO, Lund PK. IGF-I and TGF-beta1 have distinct effects on phenotype and proliferation of intestinal fibroblasts. Am J Physiol Gastrointest Liver Physiol 2002; 283: G809-818.

[30] Simon-Assmann P, Kedinger M, De Arcangelis A, Rousseau V, Simo P. Extracellular matrix components in intestinal development. Experientia 1995; 51: 883-900

[31] Sziksz E, Pap D, Veres G, Fekete A, Tulassay T, Vannay A. Involvement of heat shock proteins in gluten-sensitive enteropathy. World J Gastroenterol 2014; 20: 6495-6503.

[32] Sziksz E, Vörös P, Veres G, Fekete A, Vannay Á. Coeliac Disease: From Triggering Factors to Treatment. International Journal of Celiac Disease 2013; 1: 9-13

[33] Trier JS. Celiac sprue. N Eng J Med 1991; 325: 1709-1719.

[34] Verbeke S, Gotteland M, Fernandez M, Bremer J, Rios G, Brunser O. Basement membrane and connective tissue proteins in intestinal mucosa of patients with coeliac disease. J Clin Pathol 2002; 55: 440-445.

[35] Yasui H, Andoh A, Bamba S, Inatomi O, Ishida H, Fujiyama Y. Role of fibroblast growth factor-2 in the expression of matrix metalloproteinases and tissue inhibitors of metalloproteinases in human intestinal myofibroblasts. Digestion 2004; 69: 34-44.

[36] Zemskov EA, Janiak A, Hang J, Waghray A, Belkin AM. The role of tissue transglutaminase in cell-matrix interactions. Front Biosci 2006; 11: 1057-1076. 